\title{
Toda palabra viva
}

\section{(Guion para cortometraje basado en el relato "Toda palabra viva" de Ramón Vera-Herrera)}

\author{
Zuiri Méndez Benavides
}

\section{Objetivo (Idea)}

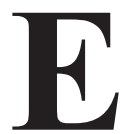
n la comunidad de Bancos de San Hipólito, Raúl, un viajero, es picado por una alacrana centurión en medio de la noche. El veneno es tan poderoso que aparte de los terribles dolores y la posibilidad de causar la muerte, también es un oráculo. Los toruka (alacrán en wirárika) son mensajeros, portadores de avisos cruciales. Mientras el viajero lucha contra el dolor, se abre un camino al pasado que revela la historia de lucha de la comunidad por la tierra.

El veneno es controlado por un suero antialacránico y el viajero puede asistir a la asamblea comunitaria. Todo el pueblo tiene que ver con su picadura. La asamblea transcurre debajo de un árbol. La comunidad alrededor de la comida, decide seguir luchando por sus tierras.

\section{Formato}

HDV 1280x720 1080i 60 cuadros por segundo.

Tratamiento de color: blanco y negro.

\section{Escenario}

Sierra Huichola. Bancos de San Hipólito. "Vallecito aislado, arrinconado contra macizos enormes de farallones, riscos, peñas y cerros que se suman unos con otros para darle al entorno una expresión de verticalidad."

\section{Personajes}

Manuela. Mujer de cara ancha y hermosa, unos 45 años, atuendo wirárika.

Catarino. Esposo de Manuela, 50 años, con poca barba, usa vestimenta de autoridad comunitaria.

Raúl. Unos 35 años. Moreno, barba, ojos negros.

Alicia. Unos 35 años, cabello café, lacio, morena y ojos claros con rasgos fuertes, cejas anchas.

Paco. Unos 35 años, pareja de Alicia, barba, simpático, castaño, risado. 
Don Simón. Marakame de 100 años, el más viejo de Bancos.

Hombre del pasado. Se parece a don Simón.

Mujer del pasado. Señora de setenta años, pelo largo con canas en trenza.

\section{ESCENA 1}

Atardece en Bancos de San Hipólito, Durango.

Niños miran con respeto un alacrán que encuentran entre las piedras donde estaban jugando. Manuela los observa mientras cuida un fuego que encendió en medio del campo para calentar atole. Están en medio de la siembra.

Manuela (en wirárika).

El toruka es el sabio más antiguo, son mensajeros, pero pilas niños, que no les pique así de chiquitos porque podrían morir.

\section{ESCENA 2}

El viento corre entre los cactus a lo alto de la sierra Huichola.

Un auto va recorriendo la carretera en medio del desierto. Los viajeros van en silencio escuchando. Viene la tormenta de ensamble kafka.

El viento mueve el polvo al frente de la casa. Manuela sale de la casa y mete las gallinas y guajolotes en su corral. Los niños salen al encuentro con su mamá y ella les indica (en wirárika) que recojan unos troncos de madera para el fogón, mientras ella recoge un saco de maíz. El maíz es de colores azules y rojos. Catarino entra a la casa con el machete y lo cuelga en el espacio de herramientas.

Manuela (en wirárika)

-Mañana llega a la reunión la familia de Hipólita. Estoy muy contenta de verla.

\section{Catarino}

-¡Qué bueno! Ya son varios meses sin verlos.

Se escucha el motor de un carro.

La pareja sonríe.

Suenan voces en castellano a lo lejos y las puertas del auto cerrándose (Alcánzame la maleta).

\section{Raúl}

Manuela, Catarino, qué alegría llegar (en wirárika)

Entran Alicia y Paco. Se abrazan y saludan todos en wirárika.

Manuela (en castellano)

-Vamos, dejen sus cosas por aquí.

\section{ESCENA 3}

De noche en casa de Manuela y Catarino.

Catarino está preparando unos papeles y le ayuda a su esposa a calentar el pozol y les sirve a los niños en unas tacitas de plástico. La esposa de Catarino prepara unas tortillas con un guiso delicioso, comen junto a los viajeros. Catarino continúa preparando los papeles. Manuela saca sus shakiras para tejer. 


\section{Paco}

-Encontramos lo que nos pidió la asamblea, Manuela, pudimos dar con los expedientes de los Títulos Primordiales de San Lucas de Jalpan.

\section{Alicia}

-En uno de los títulos aparece el nombre de Gerónimo Atales, que es cora, pero en la misma tierra, aparece también un expediente de don Ramiro, marakame de esa época. Pero todavía no podemos empezar un proceso administrativo por ahí, hasta que sepamos qué pasó con don Ramiro.

\section{Manuela}

-Don Ramiro fue el bisabuelo de Catarino. El pueblo sabe qué fue lo que pasó.

\section{Raúl}

-Pero cómo lo probamos, viene la familia de Hipólita a la asamblea.

\section{Paco}

-Genial, podemos hacer un registro de testigos.

(Viajeros se van a dormir).

\section{ESCENA 4}

Madrugada y viajeros duermen. Hace mucho calor.

En el techo de palma de la casa camina una alacrana. Cae encima de la panza de Raúl. Raúl siente sus patas rasposas e instintivamente la avienta entre la oscuridad. La alacrana lo pica en un dedo y sale volando hacia el pelo del viajero, cerca de su oreja. Con la mano sana de nuevo la lanza lejos, recibiendo una segunda picadura.
Mascullando insultos se levanta buscando el bicho. La encuentra a los pies de la cama improvisada y con un papel la empuja a un jarro, dejándola prisionera.

Alarmados sus compañeros no saben qué hacer.

Raúl siente un dolor como descargas eléctricas por los brazos. Pálido, suda y siente mucha saliva en su boca.

\section{Alicia}

-Necesitas caminar, vamos a que respires aire fresco.

(Salen de la casa).

\section{ESCENA 5}

Está en San Lucas de Jalpan, pueblo de mestizos junto a los Bancos. Raúl camina por una de las calles, solo ve sus pies con guaraches. Alicia y Paco caminan a su lado.

En la cantina hay hombres blancos, tienen trajes de más antes, de cuando empezaron a colonizar San Lucas. Él entra a la cantina y le sirven un trago, llega otro indígena y le dice que tiene una mala noticia.

Hombre del pasado:

-Los cristeros mestizos llegaron porque perdieron su guerra. Ahora quieren quedarse con nuestra tierra.

Raúl lo sigue por las calles, está confundido, el cielo está muy transparente, las estrellas brillan definidamente.

Llegan a una choza más alejada del pueblo, donde lo recibe una mujer, ella lo 
lleva a caminar por el monte. En el monte ve a un niño jugando en un árbol, tirándose de clavado en un montón de hojas secas apiladas. Raúl sonríe dulcemente. La mujer lo toma de la mano y le da un caracol.

\section{Mujer del pasado}

- Ya no puedo seguir en este mundo Raúl, ellos seguirán quemando nuestras casas y las autoridades agrarias les darán a ellos los títulos de propiedad.

Raúl mira su mano. El caracol es ahora una pequeña llama que brilla. Él se asusta y la deja ir, la llama se convierte en una luciérnaga que se junta con más luciérnagas que hacen una gran constelación.

Raúl mira maravillado el desierto de estrellas.

Raúl (piensa). ¡Tengo mucha sed!

Alicia le alcanza una jacarita con agua.

\section{Alicia}

-Viste esos hermosos venados. (Empieza a hacer un rezo en wirárika). No dejes ir la palabra nosotros, es palabra viva.

Raúl ve como las piedritas del desierto se estremecen cuando las acaricia, estas a su vez, mueven el polvo, el viento, las flores de los cactus. Hay una luz muy tenue que entre tantas estrellas recorre a Alicia, a Paco, a la mujer que le dio el caracol.

Pero lo recorre un dolor espantoso, siente choques eléctricos en sus brazos. La mujer ha desaparecido. Él ve a un mestizo cerca, tiene uniforme de soldado. Todo se hace oscuro. Está en un cuarto negro, muy negro.

\section{Raúl:}

-Seguro esto es un cuarto de tortura. Seguro esto es una probadita de lo que puede sentir alguien a quien torturan.

(Escucha un murmullo). Esta es una fosa, me han desaparecido.

Raúl abre los ojos, respira muy hondo, aunque fue horroroso lo que acaba de sentir, tiene una calma inmensa, lúcida, casi gélida. Sus compañeros lo miran tierna, preocupada y fijamente.

(Se abre la puerta).

\section{ESCENA 6}

Es de noche. Hace calor. Catarino llega al rancho. Está muy preocupado. Inspecciona la alacrana en el jarro.

\section{Raúl}

-Siento dormidos casi hasta los hombros.

\section{Catarino}

-Hay que matarla.

\section{Raúl}

-No, yo nunca mato los alacranes.

\section{Catarino}

$-¿$ Tienes visiones, te sientes bien?

\section{Raúl}

-Ahí la llevo, sí. Todo lo veo con más volumen, los colores son muy definidos, aún en la penumbra. Veo rostros de gente que conozco, me vienen emociones, pienso algo y luego alguno de mis compañeros lo dice, luego me llegan sensaciones de muy antes, situaciones que he vivido, certezas que me sorprenden. 


\section{Catarino}

-Es que el alacrán es el sabio más viejo que hay en la tierra, hazle caso. Hay algo que te está diciendo, hazle caso.

\section{Raúl}

-Y entonces, ¿por qué matarlo?

\section{Catarino}

(Rápido en responder.

Pues son muy sabios de antes pero igual te chingan los muy cabrones, no hay que dejarlos.

Tira la alacrana al piso y la aplasta.

\section{Catarino}

-Mira, ahorita sí te sientes bien, pero si te empiezas a poner malo nos tenemos que ir a la clínica de los mestizos, allá en San Lucas, y la verdad quién sabe cómo nos vaya. A los pinches vaqueros no les gusta que vengan, porque sienten que se les mueve el piso. Mejor te inyectamos suero antialacránico en la clínica de acá. Eso si hay.

\section{ESCENA 7}

Amanece en Bancos de San Hipólito. Un marakame se acerca a la casa de Manuela y Catarino.

El marakame entra a la habitación en donde está Raúl. Se parece mucho al hombre del pasado.

Paco, Alicia y Raúl le sonríen.

Don Simón les devuelve la sonrisa.

\section{Don Simón}

-Vamos a la clínica para que te inyecten el suero antialacránico.

\section{ESCENA 8}

La comunidad va llegando poco a poco, viejos, jóvenes, mujeres y niños y se acomodan debajo de una enramada que les protege de los rayos del sol, que reflejado por enormes macizos, más que dar sombra, da luminosidad y calor.

Se acerca señora. Raúl no durmió toda la noche y tiene los brazos entumidos.

\section{Señora de setenta años}

-Supe que estás malito. (En voz baja)

Tómate esta canela y te vas a sentir mejor.

-Sabes (se dirige a Paco) anoche los teruka picaron a cinco personas.

Durante la asamblea van hablando de los problemas agrarios, la situación de indefensión, la búsqueda de solución, los trabajos productivos, la organicidad.

Las mujeres comenzaron a llevarles almuerzo que circula en toda la asamblea, con frijoles, guisos con nopales, atole de maíz, huitlacoche, tortillas, dulces, mangos.

Todos le preguntan o comentan de diferentes maneras por su estado de salud.

Se van moviendo en una lenta coreografía alrededor de la sombra del gran árbol.

Las mujeres también participan de la asamblea mientras tejen o bordan. Ya sea 
en grupos o con sus maridos. Los niños también están presentes.

Otros caen en un adormilamiento, mientras otros escupen, fuman mapuche o tabaco comercial, pero se mezcla con coros, coros de conversaciones que se difuminan hasta el atardecer.

Atardece.

Entonces, cuando habla una de las mujeres, sale de su boca como un brillito, como el que vieron anoche y que hacía mover las plantitas. Paco, Alicia y Raúl se miran.

La asamblea es una fiesta.

\section{Paco}

-Saben (se dirige a Alicia y Raúl), dicen que nada sucede por coincidencia, que todo es paralelo.

Aparece una luciérnaga.

\section{ESCENA 9}

En fondo negro (suena Ensamble Kafka, Mediu Xinga).

Cuando te pique un alacrán, apaga tu fuego y ponte alerta. (viejo proverbio wirárika).

\section{Referencia}

Vera-Herrera, R. (2005). Veredas, historias en los filos del mundo. México: Itaca. 